\title{
地方师范院校国家一流化学专业建设探索与实践 以安庆师范大学化学专业为例
}

宋小威，徐衡”，王钧伟，夏宏宇，高迎春

安庆师范大学化学化工学院, 安徽 安庆 246133

摘要: 中国高等教育进入发展的新时代, 地方师范院校的专业建设在 “双万计划” 的实施下迎来了发展的大好机遇。 以安庆师范大学化学专业为例, 经过 40 多年的办学, 专业定位、师资队伍、教学资源、教学改革、实践教学以及质 量监控等专业内涵建设成效明显。站在国家一流专业建设的新起点, 笔者从建设一流课程、实施协同育人、优化师 资结构以及建立外部评价四个方面着手，就国家一流专业建设进行了初步探讨。

关键词：地方师范院校；一流专业；课程建设；师资结构；外部评价

中图分类号: G64; O6

\section{Research and Practice on the Construction of National First-Class Chemistry Major in Local Normal University: Taking Chemistry Major of Anqing Normal University as an Example}

Xiaowei Song, Heng Xu *, Junwei Wang, Hongyu Xia, Yingchun Gao

School of Chemistry and Chemical Engineering, Anqing Normal University, Anqing 246133, Anhui Province, China.

\begin{abstract}
In the new era of China's higher education development, the major construction of local normal universities is facing the great opportunity for development driven by the "double ten thousand plan". Taking chemistry major of Anqing Normal University as an example, through more than 40 years' running, the connotation construction of chemistry major such as professional orientation, teaching staff, teaching resources, teaching reform, practical teaching and quality control has made remarkable achievements. Standing at the new starting point of national firstclass major construction, the authors make a preliminary discussion on the construction of national first-class major from four aspects: building first-class curriculum, implementing collaborative education, optimizing teacher structure and establishing external evaluation.
\end{abstract}

Key Words: Local normal university; First-class major; Curriculum construction; Teacher structure; External evaluation

2019年底, 教育部公布了首批一流本科专业建设点名单, 要求获批建设点以新时代新思想为统 领, 完善专业建设规划, 持续提升专业水平, 发挥示范领跑作用。一年来, 获批建设点全力推进一 流专业建设工作 ${ }^{[1-3]}$ 。安庆师范大学化学专业自1977年创办以来, 经过几代人接力建设, 先后入选国 家级特色专业建设点、省级一流品牌专业建设点和国家一流专业建设点。经过40多年的发展，化学

收稿: 2020-12-03; 录用: 2020-12-23; 网络发表: 2021-01-04

“通讯作者, Email: xuheng@aqnu.edu.cn

基金资助: 国家级一流本科专业建设点项目(2019 年); 2018-2020 年安徽省一流(品牌)专业(2018ylzy068); 安庆师范大学教学研究项目校本综合 性化学实验课程建设(2018aqnujyxm008) 
专业建设始终以学生为中心, 以产出为导向, 积极融合多方资源要素, 在专业定位、师资队伍、教 学资源、教学改革、实践教学以及质量监控等方面扎实推进专业内涵建设, 成效明显。然而, 在国 家一流专业建设过程中, 我们面临了一流课程建设效果不明显、协同育人机制执行不深入、师资队 伍结构不协调以及人才培养质量外部评价不完善等问题, 我们在此对这些问题做出了一些思考, 提 出了一些解决策略。

\section{1 专业内涵建设成效}

\section{1 找准专业定位, 谋求专业特色发展}

我校化学专业自创办以来, 一直致力于培养化学师范人才, 为社会输送了一大批优秀的基层教 育工作者。近年来学校提出 “举师范旗, 走应用路, 创特色牌” 的办学思路, 化学专业作为老牌师 范专业, 坚持 “举师范旗” , 深化师范人才培养, 责无旁贷。然而, 随着基础教育对化学教师需求 趋于稳定, 学生在毕业时选择面变宽, 部分学生具有强烈的从教意愿, 部分学生则希望继续深造攻 读研究生, 因此专业定位也有所改变。自2008年以来, 化学专业实施人才分类培养模式, 围绕学生 兴趣与潜能, 重点培养师范型学生的教师教育技能、学术型学生的科研创新能力。对于师范型学生, 针对本区域特别是农村中学实际需要, 构建以 “顶岗实习、顶岗支教” 为特色的实践教学体系, 推 行 “U-G-S” 协同育人的培养模式, 即大学(University)-地方政府(Government)-中学(School))三方联动 培养师范型学生; 对于学术型学生, 构建以 “科研帮带、实训锻炼” 为特色的科研创新训练体系, 推行本科生导师制和校企合作育人模式。以市校合作为契机, 与安庆市高新区众多化工医药企业、 安庆市多所省级示范中学开展合作, 联合开设 “中学化学名师讲坛” “企业家进课堂” 等特色课程, 以地域特色资源培养学生专业能力。

\section{2 加强师资队伍, 夯实人才培养根基}

化学专业结合学校 “天柱学者” 人才计划, 加大人才 “引、培、稳” 力度, 积极引进高水平博 士、教授, 组建高水平的教学团队。现有专任教师 37 人, 其中教授 12 人、副教授 16 人, 具有博士学 位者 22 人, 博士生导师 4 人, 硕士生导师 28 人, 具有海外留学经历人员 2 人, 具有博士后经历和正在 从事博士后工作的教师 10 人。组建了无机化学、有机化学、分析化学和物理化学四个高水平教学团 队, 其中无机化学、有机化学和物理化学教学团队入选省级教学团队。充分发挥教学团队的 “传、 帮、带” 作用, 青年教师与团队老教师结对, 实施青年教师导师制度, 加快青年博士教师的成长。 为凸显师范专业特色, 不断加强化学教学论师资建设, 现有化学教学论教师 4 人, 从安庆一中、安庆 石化一中等省级示范高中长期聘请了4位中学化学骨干教师为兼职教师, 形成了一支以专职为骨干、 兼职为补充的化学教学论师资队伍。

\section{3 优化资源配置, 提升实践教学条件}

化学作为实验性学科, 专业人才培养离不开高质量的实验条件。学院建有无机化学、物理化学、 分析化学和有机化学四个基础化学实验室、化工基础实验室和省级虚拟仿真实验中心。通过实验平 台的建设, 开发出 20 余个特色综合性创新性实验项目, 出版了《基础化学》教材一套, 供全校选修 化学课程的学生选用。随着中学化学教育对师范生实验教学技能要求的提高, 2019年新建设了 2 个数 字化化学教学论实验室, 为学生开设数字化实验项目, 包括手持技术测定中和滴定反应、测定化学 反应速率、理解离子反应的实质、测定冰醋酸的电离度等。服务师范生教学技能提升, 建有微格教 学训练中心, 常年向师范生开放。围绕化学学科, 建有光电磁功能材料省重点实验室、光电磁功能 配合物和纳米配合物省重点实验室以及石油化工新材料省级协同创新中心三个省级科研平台, 拥有 大型仪器设备30台, 全部服务于本科实验教学。

化学专业积极拓展校外实践教学资源, 以市校合作为契机, 与安庆一中、安庆二中等省、市级 示范中学共建了 23 个教育实习基地, 保障师范生教育见习、研习以及实习开展; 与安庆市高新区共 建校企合作实践教育基地, 通过安庆市高新区相关部门收集园区企业需求, 根据需求, 分派学生到 园区的化工企业进行科研创新实践, 例如中胥新材料(安徽)、安庆飞凯新材料、安徽海康药业等。 


\section{4 以学生为中心, 深化教学全面改革}

以本为本, 不断优化培养方案。化学类教学质量国家标准对专业人才培养规格、教学条件、知 识体系和课程体系做出了明确的指导, 中学教育专业认证标准对师范专业人才培养提出更加具体的 要求。对标国家标准和专业认证标准, 化学专业对人才培养方案进行了全面修订, 从 “一践行、三 学会” 角度对毕业要求进行了规定, 进一步优化课程体系, 压缩总学分, 将实践课程和创新创业课 程的学分比例由 $15.5 \%$ 提升到 $26.3 \%$, 力图打造 “金课”、减少 “水课” , 提高学生实践创新能力。

以学生发展为中心, 探索课堂教学改革新路径。推进混合式教学、探究式教学和翻转课堂教学 的改革与实践。在教学中引入第二课堂, 建立教师教学答疑制度, 通过线上或线下答疑的方式将课 堂延伸到课外, 强化育人理念, 提高学生学习效果。

加强学习过程管理, 提升课程学习难度, 将学生学习过程考核与期中、期末考核相结合, 强化 学生学业过程评价。探索形成性评价和终结性评价考核制度。学生评教满意度明显提升, 教师也更 加积极主动地对教学手段和课程考核进行改革。近三届毕业生英语 CET四级考试平均通过率为 $86.2 \%$, 英语CET六级考试平均通过率为 $50.8 \%$, 省级计算机二级考试平均通过率 $99.6 \%$, 教师资格证 通过率达 $86.9 \%$, 就业率稳定在 $94 \%$ 以上。

\section{5 重视实践教学, 增强学生职业能力}

以产出为导向, 重视实践教学, 增强学生科研和从教职业能力。除开设基础化学实验、教育实 习外, 还通过本科生导师制、基础实验室开放和科研平台支持本科生创新实践项目等方式拓宽学生 实践锻炼渠道, 提高师范型学生从教技能和学术型学生科研能力。针对师范型学生, 选派教师指导 学生参加师范生教学技能大赛, 创新教学方法, 锤炼教学技能。针对学术型学生, 通过本科生导师 制, 学生在大一下学期就可以进入导师实验室, 参与导师课题研究, 锻炼实验技能。基础化学实验 室采取预约开放的形式, 供学生开展综合性创新性实验, 针对承担大学生创新训练项目的学生, 采 取全天候深度开放。同时, 省级科研平台面向本科生设置科研创新课题, 供学生选择, 例如 2019 年 光电磁功能材料省重点实验室面向本科生设有磷酸钒锂材料改性、磁控溅射镀铝工艺、水溶性聚合 物荧光传感器和共轭微孔聚合物材料等科研创新项目, 吸纳了 20-30名优秀的本科生参与到实验室 教师的科研工作中。近三年化学专业学生在全国师范生教学技能大赛、安徽省高等学校大学生化学 竞赛、“互联网+” 全国大学生创新创业大赛和 “挑战杯” 全国大学生课外学术科技作品竞赛等赛事 中获二等奖以上近 30 人; 1 名在读学生通过师生共同成果转化, 成立了新能源科技公司并入驻省级创 新创业捊化器。

\section{6 树立质量观念, 建立质量监控体系}

按照科学化、规范化、系统化的原则, 在教学管理人员职责、教学运行、实践与创新创业、教 学改革研究、教师能力发展以及教学质量监控等方面建有完善的管理制度, 使教学的各个环节、各 个方面都有章可循、有据可依。在专业建设、课程建设、课堂教学、实验教学、教育实习、实验室 建设、实习基地建设等方面建立了质量标准, 使关键教学环节更加标准化、规范化。在制度保障的 同时, 也建立了较为完善的校院两级质量监控体系, 对教学各个环节信息进行多渠道收集, 形成评 价结论和诊断意见反馈到专业教学上, 以进一步提高教学质量。

\section{2 一流专业建设面临的新问题 \\ 2.1 一流课程建设效果不明显}

课程建设是专业建设的基础, 是实现人才培养目标的基本途径, 一流专业建设需要一流课程建 设来支撑 $[1,2]$ 。近年来化学专业在课程建设中取得了一些进展, 物理化学和无机化学先后获得省级精 品课程和省级MOOC建设, 但是目前没有课程入选国家级一流课程建设, 打造 “金课” 的任务还很 重。究其原因, 可能与一流课程建设意识不够、课程建设思路不清、教师参与积极性不高、经费投 入不够等方面有关。通过调查发现, 大部分教师对一流课程建设政策了解不够, 缺乏课程建设的意 
识; 目前一流课程建设主要依靠教学团队负责人自发组织, 缺乏系统性规划; 参与课程建设的教师 在职称评定和其他方面并没有获得实质性支持, 参与建设的热情并不高; 课程建设需要建设经费, 但产出与投入不成比例, 经费投入并不多。

\section{2 协同育人机制执行不深入}

学校与地方政府进行市校合作, 建有 “三位一体”协同育人机制, 要求专业和中学双方进行 “协 同教研” “双向互聘” “岗位互换”, 但合作双方本职使命不同, 各自育人任务都比较繁重, 造成 交流不够充分, 合作不够深入。教育实践课程通常配备校内导师和校外导师组成 “双导师”, 因校 外导师待遇不明确, 评价机制不健全, 落实全靠校外导师的责任心。教师的社会服务还未完全实现 制度化, 化学教学论教师深入中学实践的时间并不多, 协同教研成果很少, 很难谈得上教研成果促 进教学。

\section{3 师资队伍结构不协调}

作为一流专业建设的基础要素, 师资队伍的建设至关重要 ${ }^{[4]}$ 。化学专业师资队伍基本可以满足 当前办学需要, 但与建设一流专业的要求相比, 仍有一定差距, 比如作为师范专业, 从事化学教学 论教学和研究的教师数量严重不足; 国际化背景教师数量明显不够 ${ }^{[5]}$ 。近年来化学专业希望引进化 学教学论博士或者有海外背景的高层次人才充实师资队伍, 而每年全国化学教学论专业的博士毕业 生较少, 各高校对此专业人才的需求量又较大, 致使我校长期招聘不到化学教学论专业的高水平人 才。同时本专业也希望引进海外留学经历的博士或者其他高层次人才, 受学校地理位置和办学条件 影响, 人才聚集缓慢, 本专业具有国际化背景教师较少, 教师国际交流力度不够, 专业发展也受到 较大影响。

\section{4 人才培养质量外部评价不完善}

人才培养质量的高低需要外部去评价, 化学专业虽建有校院两级质量监控体系, 但是外部质量 评价与监控体系还不完善 ${ }^{[6]}$ 。用人单位、家长和毕业生等利益相关方参与人才培养质量的评价与监 控的积极性不高。即使通过第三方机构进行评价, 用人单位和毕业生跟踪调查的反馈率也不高, 无 法充分利用外部评价结果促进人才培养质量的提升。究其原因, 可能化学专业在校友资源管理与利 用、用人单位关系维护等方面做得还不够精细。毕业生跟踪调查反馈和用人单位回访还未形成常态 化机制。

\section{3 一流专业建设的几点思考}

\section{1 加大投入, 打造一流课程}

组织化学专业教师认真学习领会《教育部关于一流本科课程建设的实施意见》和《“双万计划” 国家级一流本科课程推荐认定办法》等文件精神, 提升教师一流课程建设的意识。根据现有课程建 设基础, 出台课程建设的规划, 突出建设重点。例如, 物理化学、无机化学为省级精品课程和省级 MOOC, 以此为基础, 强弱项, 补短板, 改造并申报线上线下混合式一流课程; 有机化学为省级精 品线下开放课程, 课程基础扎实, 积极申报线下一流课程; 化工基础实验为省级虚拟仿真项目建设 课程, 课程建设前期积累较好, 有条件冲击虚拟仿真实验教学一流课程。

聘请一流课程建设方面的专家对课程建设负责人进行辅导, 指导课程内容改造、课程教学方法 和考核方式变革。落实课程建设负责人制度, 给课程负责人认定年度工作量, 参与年终绩效分配; 鼓励其他教师积极参与课程建设, 在职称推荐和教学能力提升培训方面给予优先支持。积极争取来 自上级部门、地方和社会的项目资金, 设立院级质量工程项目, 支持教师在课程思政、学科前沿知 识整合、教学方法、课程评价方式等方面进行改革创新, 形成特色课堂和亮点课程, 提升课程 “创 新性” 和 “高阶性”。

\section{2 密切合作, 推进协同育人}

学校、中学、教育行政管理部门三方密切合作, 协商细化工作机制, 明确各自权责, 建立清晰 
的工作量核算机制, 拨付专门资金, 支持 “协同育人” 工作开展。对三方具体参与此项工作的人员 支付相应的酬劳, 尤其要提高校外导师津贴标准。教育行政部门要在教研项目立项、教学成果评奖、 职称评审等方面对做出显著成绩的 “校外导师”给予倾斜。

进一步强化教师的中学实践经历和服务意识, 从制度层面规定教师参与中学 “协同教研” 的职 责和要求, 实现教研成果促进教学。实行教学论教师到中学轮岗制度, 一个聘期服务中学不少于 6 个 月。充分利用在中学任职的优秀校友, 聘请他们作为师范生 “第二班主任” , 指导师范生职业生涯 规划、“三字一话” (钢笔字、毛笔字、粉笔字和普通话)技能训练、阅读名著、教育见习、实习和教 育课题研究等。定期聘请中学校长和中学化学名师为本科生开设 “中学化学名师讲坛”, 从一线教 学、教学管理视角剖析中学化学教育教学改革、教学研究、教学实践、课堂管理、班主任工作经验, 帮助学生对教师职业的理解, 树立教师职业的信念, 增强专业发展意识。建立师范生 “双导师” 工 作台账, 实行学年登记制度, 跟踪师范生 “双导师” 执行情况, 对责任心强、工作效果好的校外导 师进行奖励。

\section{3 内培外引, 调整师资结构}

按照急需人才引进方式, 加大化学教学论教师引进力度, 在引进后给予政策倾斜, 支持他们到 境内外进行研修, 吸收国外先进教育教学思想。将内培和外引相结合, 在化学专业现有的专任教师 中进行摸底, 对有意愿专职从事化学教学论教学和研究的教师, 鼓励他们进行转型或转岗, 并积极 推荐到中学教学一线进行实习锻炼, 并优先选送到境内外访学研修, 增强其教育教学经历。在同等 条件下, 优先推荐化学教学论教师申报高一级职称, 增强他们的工作积极性。

\section{4 跟踪问效，建立外部评价}

完善毕业生长效跟踪反馈机制, 结合学校校友信息管理系统, 从学生毕业开始即着手建立毕业 生档案袋, 定期走访毕业生比较集中的地区, 及时掌握毕业生就业方向和职业发展。继续办好 “知 名校友论坛” , 搭建多维互动平台, 提升毕业生跟踪反馈工作的互动效能。建立起定期回访用人单 位制度, 了解用人单位需求, 参与用人单位的科学研究和员工培训等工作, 帮助用人单位解决实际 问题, 建立起良好的双方关系。通过与毕业生和用人单位紧密联系, 真正建立起用人单位、毕业生、 学生家长、教育行政部门等多方评价主体共同参与的人才培养质量外部评价机制。通过外部评价, 收集用人单位、毕业生等利益相关方对培养目标、课程体系、教学内容、教学模式、教学条件等方 面的改进意见，以持续完善人才培养方案，不断提高人才培养质量。

\section{4 结语}

国家一流专业建设的几点思考是我们在实际办学中遇到问题的初步解决策略, 并无多大新意, 没有特色鲜明的解决之道, 距离建成一流专业还存在一定差距。但是我们坚持以产出为导向, 为党 和国家培育更多高素质的化学师范毕业生, 服务地方基础教育事业; 坚持以内涵建设为核心, 不断 充实专业办学条件, 服务学生成长成才; 坚持以问题为导向, 合理配置教育资源, 着重在建设一流 课程、实施协同育人、优化师资结构和建立外部评价等方面发力, 进行一流专业建设探索和实践, 逐步形成自身的优势和特色。

\section{参 考 文 献}

[1] 万坚, 邓阳, 原弘, 余能芳, 龚静鸣, 李永健, 温丽丽, 张文华, 郭能, 李武客, 等. 大学化学, 2021, 36 (5), 2007040.

[2] 纪敏, 孟长功, 姜文风, 吴硕, 赵艳秋. 大学化学, 2021, 36 (5), 2003036.

[3] 邱建华, 沈星灿, 唐劲军, 许燕红, 蒋邦平. 大学化学, 2021, 36 (5), 2010072.

[4] 许雪棠, 周立亚, 段文贵. 大学化学, 2021, 36 (5), 2008070.

[5] 王雪, 王战军. 上海教育评估研究, 2019, No. 5, 53 .

[6] 李善姬. 吉林医药学院学报, 2020, 41 (6), 436. 